\title{
Animal welfare impacts of badger culling operations
}

WE are writing to express our extreme concern following recent media coverage 1,2 relating to the methodology being used by contractors to kill badgers under licence, as part of the government's policy to control bovine TB in cattle.

The coverage relates to the shooting of badgers that have been captured in live traps. Covert video footage (https:// bit.ly/2Eud1iR ) from Cumbria shows a trapped badger being shot with a firearm at close range, following which it appears to take close to a minute to stop moving. The contractor clearly observes the animal during this time but makes no attempt to expedite

the death of the badger and prevent further suffering, as required by the current Natural England best practice guide which states: 'Immediately after shooting, the animal should be checked to ensure it is dead, and if there is any doubt, a second shot must be taken as soon as possible.' 3 The conversation between the contractor and his companion also suggests they were considering moving the badger to another site before finally bagging the carcase, again breaching the best practice guide.

While the footage only relates to the experience of a single badger, and while the degree to which the badger was conscious in the period immediately following the shot is unclear, we can by no means be certain that the badger did not suffer. It also raises serious questions about the training, competence and behaviour of contractors, in relation to both badger welfare, and biosecurity. This adds to existing concerns relating to the humaneness of 'controlled shooting' (targeting free-roaming badgers with rifles), which continues to be a permitted method under culling licences, in spite of the reservations expressed by both the government- commissioned Independent Expert Panel in its 2014 report, 4 and the BVA, which concluded in 2015 that it 'can no longer support the continued use of controlled shooting as part of the badger control policy'.5 (However, it has since continued to support the issuing of licences which permit the method). The BVA has consistently indicated its support for what it calls the 'tried and tested' method of trapping and shooting, but has thus far failed to provide comprehensive and robust evidence for the humaneness of this method.

During 2017, almost 20,000 badgers were killed under licence across 19 cull zones, around 60 per cent of which were killed by controlled shooting, the remainder being trapped and shot. 6 Natural England reported that its monitors observed 74 (just over 0.6 per cent) of controlled shooting events for accuracy and humaneness. No information has been provided on the extent to which trapping and shooting activities were monitored. This raises serious concerns about the extent of suffering that might be experienced by very large numbers of animals, for which contractors are not being held to account.

If contractors reach their maximum culling targets set by Natural England for 2018, as many as 41,000 additional badgers could be killed.7 The extent to which these animals will suffer is once again being left in the hands of contractors, with woefully inadequate oversight, and in the face of anecdotal evidence of breaches of best practice guidance. This situation is clearly unacceptable from an animal welfare perspective and it is our view that by endorsing the policy, the BVA is contradicting the principles contained within its own animal welfare strategy. 8

We therefore urge the BVA to withdraw its support for any further licensed badger culling, and the RCVS to make it clear that any veterinarian who provides support for culling activities that result in unnecessary and avoidable animal suffering could face disciplinary proceedings. The veterinary profession has no business supporting this licensed mass killing with all its inherent negative welfare and biosecurity implications, and for which the disease control benefits are, at best, extremely uncertain.

We believe the continued support for the culls by veterinary bodies in the face of poor evidence for its efficacy damages the credibility of the profession, and that same support in the face of potential animal suffering on a large scale undermines its reputation.

We stand ready to discuss these issues in more detail.

Mark Jones, Fiona Dalzell, Bronwen Eastwood, Richard Edwards, Phill Elliott, Geraldine Hale, Sophie Hill, Jo Hinde, Hannah Hughes, Andrew Knight, Joanne Lewis, Alastair MacMillan, lain McGill, Andre Menache, Richard Saunders, Alick Simmons, Peter Southgate, Kathy Tipping, Julie Turner, Guda van der Burgt,

c/o Born Free Foundation, Broadlands Business Campus, Langhurstwood Road,

Horsham, Sussex RH12 4QP

e-mail: markj@bornfree.org.uk

\section{References}

- $\quad$ Doward, J. Secret filming reveals hidden cruelty of licensed badger culls. The Guardian, 30 September 2018. www. theguardian.com/environment/2018/ sep/30/covert-footage-reveals-cruelty-of- badger-culls (accessed 16 October 2018).

- $\quad$ Anon. Culled badger took a minute to die. BBC News, 1 October 2018. www.bbc.co.uk/ news/uk-england-cumbria-45703421 (accessed 16 October 2018).

- Defra. Cage-trapping and dispatch of badgers under licence to prevent the spread of bovine 
- TB in cattle. 2018. https://assets.publishing. service.gov.uk/government/uploads/system/ uploads/attachment_data/file/740294/ badgers-cage-trapping-and-dispatch.pdf (accessed 16 October 2018).

- Independent Expert Panel. Pilot badger culls in Somerset and Gloucestershire. 2014. https:// assets.publishing.service.gov.uk/government/ uploads/system/uploads/attachment_data/file/300382/independent-expert-panelreport.pdf (accessed 16 October 2018).

- $\quad$ BVA. BVA calls for change to badger culling method and wider roll-out in England. 2015. www.bva.co.uk/News-campaigns-andpolicy/ Newsroom/News-releases/badger-cull (accessed 16 October 2018).

- $\quad$ Defra, Natural England. Bovine TB: summary of badger control monitoring during 2017. 2017. www.gov.uk/government/publications/bovine- tb-summary-of-badger-control-monitoring- during-2017 (accessed 16 October 2018).

- Natural England. Bovine TB: authorisation for badger control in 2018. 2018. www.gov. uk/government/publications/bovine-tbauthorisation-for-badger-control-in-2018 (accessed 16 October 2018).

- BVA. Vets speaking up for animal welfare. 2016. www.bva.co.uk/uploadedFiles/Content/News,_campaigns_and_policies/ Policies/Ethics_and_welfare/BVA-animal- welfare-strategy-feb-2016.pdf (accessed 16 October 2018). 